\title{
EDITORIAL
}

\section{PELAS ONDAS DA HISTÓRIA ORAL NA TRAJETÓRIA DO PROFESSOR JOSÉ CARLOS SEBE BOM MEIHY}

\author{
Maria Cristina Menezes \\ CIVILIS/FE/UNICAMP \\ mcris@unicamp.br \\ Maria de Lourdes Pinheiro \\ CIVILIS/FE/UNICAMP \\ pinheiro.lou@gmail.com
}

A apresentação do Dossiê "Patrimônio-Educativo e História oral: subjetividades e diversidades na contemporaneidade" anuncia, de início, o reconhecimento das organizadoras quanto ao vínculo com o Núcleo de Estudos em História Oral do Depto. de História da USP, criado pelo Professor José Carlos Sebe Bom Meihy, que de alguma forma em diferentes momentos as uniu. Desta feita, as Professoras Andrea Paula dos Santos Oliveira Kamensky, Maria Lucia Mendes de Carvalho e Suzana Lopes Salgado Ribeiro são unânimes em afirmar que as leituras e referenciais teóricos que nortearam e norteiam as escolhas para a trajetória acadêmica que perseguiram, ao buscarem a História Oral, tem como ponto de partida o Professor Meihy, cuja produção as fundamentou no desenvolvimento das pesquisas e fazeres acadêmicos.

Entrevistar o Professor Meihy em "Gostaria de ouvir todas as histórias que puder. Todas." - Entrevista com o Professor Dr. José Carlos Sebe Meihy, possibilitou às Professoras Andrea Kamensky e Suzana Ribeiro a homenagem "de quem foi formado por um grande mestre" àquele do qual se orgulham do convívio e aprendizado. Aos leitores da RIDPHE_R possibilitam aproximação a um processo de criação e implementação da História Oral que se desdobra ao se percorrer a trajetória acadêmica do Professor Meihy em "sua história com a história oral".

A entrevista vem imediata à apresentação, uma vez que a primeira remete à segunda.

Ler o texto da entrevista do Professor Meihy é desbravar uma história, trata-se de entrevista emblemática, diante do significado social e histórico que a reveste. Nela se tece o percurso do historiador, entrelaçado ao da história oral por ele introduzida e vivenciada, junto a tantas (os) outras (os) investigadoras (es) que se agregaram ao NEHO, Núcleo de Estudos em História Oral no departamento de história da USP (NEHO/USP).

No NEHO/USP, o Professor Meihy que diz nunca ter concebido como ideal, no campo da História, explorações que se esgotam na leitura de pensadores, uma vez que 
para ele não se pode falar de teoria sem pesquisa empírica, promoveu o debate voltado à aproximação das abstrações teóricas com a iniciação em pesquisas de campo.

A afirmação de que as fronteiras da História Oral são bastante porosas remete ao expressivo número de artigos enviados após a divulgação do presente dossiê. Fato que moveu a RIDPHE_R à organização de mais de uma edição sobre o tema, uma vez que se prepara uma próxima edição com artigos articulados a temática para início de 2019.

De outra feita, podem ser elencadas tantas mais possibilidades abertas às pesquisas pela via apresentada a partir da História Oral. Via da qual não escapam as pesquisas na área da história da educação, quer seja diante do alargamento das fontes, com a proximidade aos novos estudos advindos, em especial, da história cultural, quer seja estimulada pela ampla discussão sobre memória que ganha terreno e alça a oralidade à proeminência, como anuncia o Professor Meihy, sobretudo, diante da consideração de que na história os sujeitos são coletivos, ainda que no grupal emerja a individualidade.

No sumário, em continuidade à apresentação e à entrevista ao Professor Meihy, buscou-se articular os artigos, ou entendê-los pelas veredas do já enunciado.

O texto "Quando eu estudava no Uruguai..." ...": a escola recordada por estudantes de um grupo escolar em Porto Alegre/RS (1948 - 1954)", traz, sob o olhar de cinco alunos do Grupo Escolar Uruguai, do período destacado, as narrativas de homens e mulheres já idosos em suas percepções acerca das práticas escolares. Rememoram um tempo de outrora em que na escola tomavam a sopa, jogavam caçador, cuidavam da horta, entre tantas reminiscências, como as brincadeiras nas ruas. As autoras (es) consideram a força da memória coletiva, ao se remeterem a Halbwachs (2004, p. 31), na frase "outros homens tiveram essas lembranças em comum comigo".

$\mathrm{O}$ artigo "Aqueles tempos do Julinho: práticas no cotidiano escolar da ditadura civil-militar (década de 1970)", relaciona-se à história do Colégio Estadual Júlio de Castilhos, de Porto Alegre (RS), a partir de documentos escritos e da memória de quatro professoras que atuaram na Instituição no período supracitado. foi possível observar que mudanças significativas ocorreram no período ditatorial. Essas mudanças refletiram-se diretamente em alterações curriculares no Colégio Júlio de Castilhos. Destacam-se disciplinas de cunho estritamente ideológico, que foram acrescentadas ao currículo, bem como cursos técnicos implantados - questões que foram identificadas, sobretudo, no Regimento Escolar e no Plano Curricular. Sendo assim, a partir das memórias das professoras, percebe-se, em suas vivências, que o envolvimento com os alunos, seja defendendo-os ou conscientizando-os de sua realidade, foi de suma importância em um período de resistência e opressão. Além disso, ao rememorar 
acerca de um ambiente escolar, onde múltiplos atores coexistiram, torna-se inevitável uma história perpassar e fundir-se a outra, compondo, dessa forma, uma memória coletiva, como a relatada pelas professoras. Mais uma vez, defronta-se com a memória e os seus desdobramentos.

Em "Las voces de una generación de maestros y maestras que defendían una escuela renovada, vasca y popular" configurou-se uma rede de professoras (es) que compartilhavam de uma mesma identidade profissional e diferenças em função do tipo de escola e o desejo de modernização pedagógica vinculada à incorporação da língua vasca nas escolas, e na defesa de um ensino popular. Para os autores, os testemunhos constroem um relato cronológico de uma situação política muito próxima.

Os autores ressaltam também o valor patrimonial que carregam as vozes das professoras e professores protagonistas em importante momento de desenvolvimento profissional, bem como a relevância de que o guia museográfico com o relatos da historia da educação Vasca traga a voz de seus protagonistas, no caso em questão, os professores e as professoras que protagonizaram a renovação pedagógica

O texto "Oralidad y patrimonio histórico educativo. La memoria escolar de las generaciones instruidas durante el franquismo", discute que oralidade se apresenta com muita pertinência para se obter e desenvolver o conhecimento histórico e resgatar temas que escapam ao discurso historiográfico tradicional. A proposta didática defendida pelas (os) autoras (es) busca mostrar o quão importante se apresenta oferecer através dos museus de educação, para além do contato com o patrimônio etnográfico escolar, a possibilidade, aos visitantes, de contar uma historia com o favorecimento do diálogo e a narração de experiências. As (os) autoras (es) destacam no texto a realização de visitas guiadas e oficinas com diferentes grupos, para que os mesmos possam contemplar os objetos do museu e a partir dos mesmos, das emoções suscitadas, recriar experiências de outrora.

Nesta linha dos expositores do museu de educação espanhol, o artigo "Mediadoula: atenção ao (à) visitante da exposição sentidos do nascer" discute como as exposições poderiam se valer da experiência de escuta-acolhimento. Interessante a discussão encetada sobre a escuta do(a) mediador(a) que se considera deva ir muito além de ouvir os relatos, as dúvidas e as considerações do(a)s visitantes. A escuta e, consequentemente, o diálogo estão relacionados ao acolhimento, a uma postura sensível do(a) mediador(a) frente às histórias de vidas e questões apresentadas por quem visita a exposição. Assim como o (a) visitante se envolve com a temática, o (a) mediador se afeta pelas narrativas de cada visitante, diferenciando-se da postura de mediação, cuja a escuta configura-se como uma mera 
formalidade. Cabe ainda, remeter à utilização das novas tecnologias em experiências como estas.

“Fontes orais e as práticas de alfabetização no Grupo Escolar Bom Jesus de 1955 a 1971", a história da alfabetização, no período de 1955 a 1971, no Grupo Escolar Bom Jesus em Uberlândia -MG, com o aporte teórico da Nova História Cultural, buscou novas possibilidades de pesquisa e de fontes à história da educação na história oral como instrumento fundamental à realização do estudo, partindo-se das vozes das próprias alfabetizadoras para uma reconstrução da história da alfabetização naquele Grupo Escolar. O estudo se alinha a outros deste dossiê temático ao dar voz às protagonistas desta história que se busca reconstruir.

“A história oral e sua contribuição para a recuperação da memória e da história do ensino técnico e profissional agrícola em Jacareí- SP", estudo que objetivou recuperar a história da turma feminina do curso de Iniciação Agrícola da Escola Profissional Mista Agrícola e Industrial Cônego José Bento (1948-1954) e a representação discente em relação à cultura escolar de uma determinada época. Utilizando-se das potencialidades dos procedimentos, demonstrados pelos autores acima, procedeu-se a investigação do público escolar feminino no ensino agrícola em Jacareí, SP , protagonista e parte integrante do patrimônio educativo da instituição. A partir do depoimento dos sujeitos que protagonizaram a história que se busca reconstruir é possível o fortalecimento do quadro explicativo, com o alargamento das fontes, como enuncia a autora..

"Produção de documentação oral e preservação da memória do Colégio de Aplicação da Universidade Federal de Sergipe", neste artigo a discussão se dá sobre procedimentos e resultados da composição de um "banco de histórias" a partir de narrativas de professores que exerceram a docência no Colégio de Aplicação da Universidade Federal de Sergipe entre os anos de 1959 a 1995 . As entrevistas em formato audiovisual que possibilitará, com o auxílio de novas tecnologias, adicionar novos documentos ao acervo do Centro de Pesquisa, Documentação e Memória do Colégio de Aplicação. Para além de uma pesquisa pontual, se busca salvaguardar a memória institucional com a composição de um "banco de histórias". Para além do antigo gravador, novos recursos salvam imagens e vozes. Para além da produção dos textos escritos, possibilita-se a difusão do patrimônio histórico-educativo com a ampliação de dispositivos e possibilidades de se alcançar outros públicos.

Voltando ao Professor Meihy, a questão "História Oral para quem”, ganha inerência à vida de todas (os). "A ampliação do público consumidor das experiências que nos envolve, a todos, é parte do projeto. Neste sentido, as redes sociais, a internet, o cinema e a televisão se inscrevem nos planos de divulgação". 
Os artigos que destacamos a seguir tratam de textos que lidam com o presente, com a narração de histórias de práticas realizadas em contextos diferenciados.

“A docência no contexto do curso de formação de professores indígenas no amazonas: relatos de aprendizagens", no dizer de suas autoras “...enfatiza o profundo aprendizado vivido pelos professores que se dispõem ao trabalho com os povos indígenas". Em exercício de alteridade que se explicita no texto das autoras, elas desafiam à leitura do trabalho que carrega em si nuances da diversidade cultural que se conhece ao decorrer das atividades docentes narradas. Trata-se de diálogo com a diversidade, com as diferenças.

Se o estudo acima citado pede o exercício da alteridade, na escuta da diversidade, este que nas próximas linhas se apresenta, pede atenção a identidades construídas por professoras e professores nas diferentes modalidades de ensino, na diversidade das práticas instituídas, como a jornada ampliada de escolas de ensino fundamental.

“Narrativas em rede: argumentos coletivos e histórias de vida na educação", concordando com colocações do Professor Meihy, pode-se afirmar os estudos no âmbito, em especial, da história da educação e voltados à formação de professores, mas também com a preocupação de que os olhares se voltem para as escolas e suas culturas internas. A história e as experiências não apenas de professores, como dos demais sujeitos educacionais e escolares, torna-se "um desafio que exige reflexão". Por outro lado, as marcas dos registros, nos mais diversos dispositivos, que a História Oral possibilita, são fontes, preciosas fontes, que preservadas passam a compor o nosso patrimônio histórico-educativo e cultural.

Na seção Resenha, Luciana Maria Ricci do Valle Mesquita apresenta:

\section{REDES CONECTADAS E DOCUMENTADAS}

Detém-se sobre o livro: MENEZES, Maria Cristina (Org.). Desafios Iberoamericanos: o patrimônio histórico-educativo em rede. São Paulo: CME; FEUSP, 2016. 585 p.(Série Patrimônio Histórico Educativo, Volume 1).

Resultado de interlocuções geradas no âmbito da Rede Iberoamericana para a Investigação e a Difusão do Patrimônio Histórico-Educativo (RIDPHE) e deu origem ao primeiro número da Coleção Patrimônio Histórico Educativo, sob a coordenação de Carmem Sylvia Vidigal Moraes e Maria Cristina Menezes (2016, p. 11-12).

Na seção Documento Rosângela Cristina Gonçalves apresenta:

QUINZE ANOS DA LEI 10.639/03 - AVANÇOS E RETROCESSOS 
“A Lei n 10.639, de 09 de janeiro de 2003, representa um marco histórico e simboliza a resultante conquista das lutas antirracistas, na e pela educação, lideradas pelo MNU, Movimento Negro Unificado no Brasil, e um ponto de partida para a renovação da qualidade social da educação brasileira". Ao constatar que, ainda assim, a lei não é efetivamente cumprida em função de um conjunto de intolerâncias e discriminações enraizadas na sociedade brasileira, a autora se deterá sobre esse nó, à luz da Lei que se publica na íntegra na seção.

Desejamos uma boa leitura a todas (os) e que 2019 seja um ano de lutas e conquistas! 